\title{
Photojournalism and Disaster: Case Study of Visual Coverage of Flood 2010 in National Newspapers
}

\author{
Aniqa Ali \\ Department of Media \& Communication Studies \\ International Islamic University, Sector H-10 Islamabad \\ e-mail: aniqaali29@gmail.com
}

Sana Mahmood

Media \& Communication Studies International Islamic University, Islamabad

\section{Doi:10.5901/ajis.2013.v2n9p168}

\begin{abstract}
The phenomenon of flood after rainy season is not new for Pakistan but flood in 2010 is the biggest ever and effected \& displaced millions of people from their homes. Role of photojournalist is very critical at the time of crisis as they can touch hearts by only one picture rather than using many words. Using Content Analysis technique the aim of study is to analyze photographic coverage of flood 2010 in national newspapers. The study is focused on prominent frames used in visual coverage of flood 2010. Moreover, the study also analyzed ethical issues like showing dead \& mutilated bodies, grief and gender stereotyping; in photos of flood 2010. Both English (Dawn, The News, Express) and Urdu (Jang, Express, nawa-i-waqt); are analyzed which helped in establishing the difference in visual framing of both language media. Using census sampling method all photographs (2156 photos) including hard news photos, stand alone photos, and photographs with feature stories; in above mentioned newspapers are analyzed; from July 2010 when the crisis initially started to November 2010 are included in study. Major frames found in visual coverage of flood 2010 are human interest frames, economical frame and political frame. It was observed that Human Interest Frame is dominant in all newspapers. Political frame is more prominent in Urdu newspapers. There are very less photographs portraying dead and mutilated bodies. Visuals are gender stereotypes in a way that females are dominantly framed in passive roles. This study has tried to contribute to scarcity existing in visual framing research.
\end{abstract}

Keyword: Visual framing, flood 2010 Pakistan, human interest frames, disaster coverage, gender stereotyping.

\section{Introduction}

It is imperative for journalists to consider that how visuals can shape events not only for general public but for affectees also. Journalistic interpretation of events in visuals can affect public \& governmental policy in various ways. This is very relevant in case of disasters and crisis situations. According to Sontag (1977) photographic content of newspapers depict reality more closely than text and therefore help real life understanding of events \& issues in a much better way. Research has shown that the first thing news reader look at on a newspaper page is a photograph and that photographs are highly read (Garcia, 1987; Stone, 1987). Jackson(2011) suggests that visuals create story of an event and public construe the impact \& implication of disaster through them. In his research on flood he argued that" investigating three interlocking narratives of beauty, ruin, fraternite, the article shows how photographs of Paris under water allowed residents to make sense of the deconstruction.". Lester \& Ross (2003) further argued in their book about news photographs that "They do not become iconic symbols of a particular event. Rather they serve as source of information that audience member can incorporate into their understanding of story."

The present study aims to find out what visual frames are created by national newspapers while covering photographically the biggest flood (2010) in the history of Pakistan. Studying this disaster from the perspective of visuals also helps to understand that what memories are created visually by national coverage in the mind of people after their exposure to national newspapers. Furthermore study is also focused to study visuals from gender perspective.

Due to its location and monsoon season the country has long history of floods from River Indus and its sister rivers which are seen as a foremost natural catastrophe. But the latest flood of 2010 during monsoon rains was the most 
disastrous one. It started with severe rainfall in third week of July in southern Province of Baluchistan, followed by a second spell of rains in Khyber Pakhtunkhwah (KPK) during last week of July. These rains generated extraordinary flood flows in KPK, followed by Punjab and Sindh. A representative of UNO, Maurizio Giuliano, dealing Humanitarian Affairs (OCHA) stated that flood 2010 is most horrible and worst than tsunami and earthquake in Haiti \& Pakistan.

The losses (as of Jan. 02, 2010) faced by flood were: 1,985 deaths, 2,946 injured, 1,744,471 damaged houses, 78 districts affected and the total population affected was 20,184,550 (Source: National Disaster Management Authority). With so many population affected by this disaster it was important to understand that what type of visuals are created or emphasized by national newspapers.

\section{Literature Review}

\subsection{Media Frames and Framing}

Framing research is very much limited when it deals with elements of visual framing. Thus this study can help to add in very less touched area of visual framing. While studying mass media researches, Matthes (2009) bring into notice that visuals are very less studied as compared to textual elements. After studying 131 studies published in fifteen international journals he argued that problems in "framing research is lack of operational precision, the descriptive focus of many analyses, and neglect of visuals". According to him this approach is very problematic as textual content is intrinsically affected by visuals, so role of visual elements is very crucial to framing theory. Borah \& Bulla (2006) quoted that concept of framing is firstly developed by Goffman (1974). Framing is defined by him as those rules which organize and govern an event and journalists are subjectively involved in it.

The process of framing is explained by Tewkusbury \& Schefeule (2009) and Entman (2003) as process of selecting certain words and images which emphasize a certain viewpoint or interpretation which journalists want to promote. This explains the importance of visual framing while covering disaster or crisis as it can influence public perception in the way media / journalist want which can in turn effect public's and government's response to the disaster. Fahmy ,Kelly \& Soo(2007) in their study on Hurricane Katrina defined framing as "The central idea of framing refers to the activities of the mass media in selecting, emphasizing, and presenting some, but not all, available information to the audience. The process generates a frame on inclusion and exclusion of information."

Weaver (2007) found similarities between second-level agenda setting and framing but not as identical approaches. Both of them focus on how an issue or object is depicted on media rather than which issue or object has more prominence in reporting. He concluded that framing was still not well defined, conceptually or operationally, as compared to agenda setting and priming. It was also discussed by Tewkusbury \& Schefeule (2009) that framing is somehow different from basic agenda setting concept as in agenda setting media only raises attention to certain issue but in framing media raises or tries to give interpretation to certain lines of any particular issue.

\subsection{Visual Framing}

Catastrophic events (plane crashes, natural disasters, terrorist attacks, etc.) are often given extensive visual representation in print media, which can leave lasting impressions in the minds of the public. Literature on press photography and other imaging in general tells us that just like the text, visual material is not neutral account of reality. It applies to both photographs and drawings or paintings (Kruif, 2009).

Considering much simpler and far reaching implication, the simple act of selection is visual framing. It includes choosing one view to make photograph instead of another, editing or cropping in a way while leaving other options, or display one image out of others taken at the same time (Messaris \& Abraham, 2001; Borah \& Bulla, 2006). But as discussed earlier and as posited by Matthes(2009) research on visual framing is very little especially those which are related to disaster. Downey (2012) quoted Borah \& Matthes (2009) that "Visual framing is lacking in existing research as compared to textual analysis." He further quoted Fahmy , Kelly \& Soo(2007) that though various studies were conducted on frequency of photographs appearing in media but mostly those are related to war on terrorism. Furthermore to understand coverage of any disaster, understanding of photographs can help to deeply understand media frames. Faux \& Kim (2006) explained that sometimes media use image of disaster to create 'pseudo reality' which while giving many perspectives fails to objectively record event.

While discussing the role of media in natural disasters Littlefield \& Quenette (2007) argued that media use its specific \& important position in society to create their own point of views and reality for public regarding disaster \& crisis. They found in their analysis that generally blame game is played by media regarding authority figures \& organization 
which is mostly not based on facts. They further argued that media mostly brings biasness in reporting disaster and through process of framing; both through visuals \& text , has strong hold on interpretation of disaster.

Messaris \& Abraham (2001) found that the perception of viewers about an event or object is more influenced by a photograph than words because they closely link it to the reality. That is why they claim that visual framing is "less obtrusive, more easily taken-for-granted than verbal framing" (p. 217). Visual frames can activate certain constructs in the minds of news consumers by directly influencing them at the expense of others (Kenix, Rodgers \& Thorson, 2006).

Fahmy (2004) argues in her study of portrayal of Afghan women during and after Taliban regime in AP Wire photos, that a news photograph is not the entire whole but only a part of whole, a small portion of what is really out there. She supports the point mentioned earlier that the actuality of an event or object represented in news image is influenced by media logic such that photojournalist's point of view or editorial choice. In another study on images of Hurricane Katrina; Fahmy et al. (2007) found that images from independent sources were different from images that were acquired by wire services. Borah \& Bulah (2006) did a content analysis on the photographic coverage of the Tsunami and Hurricane Katrina to study concept of visual framing. Their study compared how newspapers from three countries (India, United Kingdom, and United States) in three continents visually framed the first week of the two natural disasters. They stated that both natural disasters and war produces images that can shock the audience and it becomes difficult for an editor of a media organization to decide what to select and what to reject.

While suggesting that how visual frames are created; Kruif (2009) discusses the technicalities of photography and claims that images can not only be manipulated afterwards but during production too. The decisions are made about the subject, camera angle, lighting, and framing of the view. Newspaper editor's choice is also involved in visual framing like how and in what context an image is presented, at which position on the page, and the caption written for that image (Moriarty \& Popovich, 1991; Rodgers \& Thorson, 2000; Kruif, 2009).

Another aspect of visual framing discussed in many researches is that human interest frame is more prevalent in coverage of natural disaster, crisis and war situation (Peng 2004; Schwalbe, Silcock \& Keith 2008; Wojdynski 2009).While analyzing online source for photographs of Iraq war Wojdynski (2009) found that human interest frames based on civilians were more common than frames based on soldiers \& authority figures.

In his study using content analysis method Peng (2004) found that human interest frames are frequently used in process of visual framing. Photographic coverage of China is analyzed by Peng across ten years span in New York Times and Los Angeles Times. Peng argued that "results show a significant increase in the total number of photos in general and economic and human-interest photos in particular. While the pattern of "official" news (dominantly politics and government) continued, more average people came into the frames, and the overall tone appeared to be more positive."

Schwalbe et al. (2008) found in his study of photos of Iraq invasion by US; that in first two weeks images were framed by using political frame but after that mostly images are framed based on human angle. As argued by Lester \& Ross (2003) that emotions are central theme to human angle and photographs is best tool for depiction of emotions. They argued that "A single photograph can, nearly instantaneously, convey an emotion or emotional states. We need no words to immediately interpret sorrow on the face of young women standing over flag draped coffin."

\subsection{Gender Stereotype}

Several researches have proved that news images convey stereotypical portrayals of race, age, ethnicity and gender (Fujioka, 1999; Kahle, Yu, \& Whiteside, 2007; Kenix, Rodgers \& Thorson, 2007). Generally the technique of content analysis is used in these studies to analyze the issue of stereotyping in visuals as well as text. One of them is Fahmy (2004) who defines stereotype as an opinion about a particular group, identified by the way they are being depicted. In psychological context it is a cognitive process, an individual's perceived knowledge, beliefs and expectations about specific human groups.

A single image is not capable to stereotype. Continuous exposure to same representation of certain group by media reinforces our personal stereotypes. Lester \& Ross (2003) maintain that media stereotypes magnify an individual's stereotypes that in result lead to social disintegration; hatred, violence, and misunderstanding (p. 3).

Women are often portrayed in gender-stereotyped roles in news media like victim of violence, sex object, or suppressed by her male relations, rather than in positions of authority (Ross, 2005).Fahmy (2004) also argued that "Goffman (1976) concludes women have been portrayed as sexy, dependent, uncompetitive, passive and shy" .In study on visual portrayal of Afghan Women Fahmy(2004) argued that "Regarding the portrayal of Afghan women in subordinate traditional roles, the majority of images in both data sets, 228 photographs, depict Afghan women in inanimate positions such as sitting or standing" It is rarely that women are associated with strength. Similarly, in a study 
by Rodger, Kenix \& Thorson (2006), it was found that gender stereotypes do exist in media and women are mainly shown in stereotyped topics and sections. They quoted Van Zoonen(1995) that "some studies have found that females are more likely than males to be represented as victims in news coverage of stories about crime and violence."However in their study they found that" findings revealed that significantly more females than males were depicted as happy, calm and submissive. In contrast, significantly more males than females were portrayed as sad, excited and dominant."

\subsection{Research Questions}

- RQ1: How Flood 2010 is visually framed in National newspapers?

- RQ1a: What are the prominent frames/themes used to visually frame flood 2010 in national newspapers?

- RQ1b: To what extent themes of dead \& mutilated bodies are used in visual framing of flood 2010 in national newspapers.

- RQ2: In which role male \& female subjects are framed in visuals of all four newspapers while covering this disaster.

\section{Research Methods}

The method selected for this study was content analysis which is the best approach for this study as explained in literature (Matthes 2009; Yang 2009 ; Wojydnski 2009, Peng 2004). The reason for choosing it as methodology was that it allowed the researcher to examine that how media has created those frames rather than survey or experimental study which can help to study that how audience has interpreted those frames.

The source of sample for the photographic content of coverage of flood, 2010 was three English (Dawn , The News, Express) and three Urdu (Jang, Nawa-i-waqt , express) major dailies of Pakistan.. By major, the researcher meant the most circulated and credible newspapers published in Pakistan. By using census method of sampling every photograph published in these daily newspapers from July 2010 to November 2010 was included in study. This time span covered the crises and post crises period of the disaster. Daily issues of the above mentioned. Magazines and material other than main publication of the issue was not included in the sample.

\subsection{Instrument/Code Sheet}

Coding sheet was designed as the instrument of data collection. There were 12 main groups or categories which were further divided into sub-groups. They were:

1. Size (size in inches of picture + caption)

2. Depiction of Death/Grief (dead Body or Subject grieving over dead body, mutilated bodies)

3. Gender Stereotype Gender stereotype was measured by

- Presence /absence of male \& female subjects

- Role/action by male/female subjects is divided in

a. Passive Role of subject can be defined

- As subject being helped or lifted by others to wade through water .Subject Sitting always sitting in grief and waiting for others to help. Subject not helping others or his/her family members and not doing anything for their own self.

- Subject not working for rehabilitation and Construction.

b. Active Role of subject can be defined as

- Independent - men/women present in vicinity struggling for life.

- Standing - men/women always standing or moving in affected areas

- Subjects actively rescuing their family members or others.

- Working - men/women working for construction or rehabilitation.

4. Prominent Frames/themes

For analyzing prominent frames as studied in literature three categories were made:

- Human Interest Frames in which civilians or those affected by this disaster are shown and those which are related to getting sympathy and which can touch the emotions of audience. They are mainly sympathy seeking frames. Sympathy can be get by showing disaster \& grief of affected people so themes that can 
touch emotions and feelings of audience like showing child Misery, old People Misery, grief in General, destruction, fight over Food \& Lack of Facilities etc.

- Economic Frames can be categorized as aid assisting frames in which aid requirement is shown by portraying bad condition of heath facilities, construction facilities, and shelter, food and rescue facilities in disaster area. In this those photographs can be categorized which show bad economic condition in disaster hit area.

- Political Frames are categorized when other than civilian or those affected by this disaster are present or through which political actors can politicize the event. The subjects which can come in this category are government representatives, defense forces, politicians, NGOs, International actors etc.,

Data is retrieved from hard copy archives of newspapers and they were collected according to date. After that all photos from each issue is collected regarding flood 2010. An image is analyzed only once; if any image is repeated than it was not again made part of the study. Data is then analyzed using SPSS Statistical software. Non parametric test like chi square is used because data is nominal or categorical level.

\section{Results \& Analysis}

Data were collected from the printed copies of the newspapers and a total of 2156 photographs were retrieved from the four newspapers; 1015 images of English newspapers (Dawn: 383; The News: 289, Express (eng): 343) and 1141 pictures of Urdu newspapers (Nawa-i-waqt: 352; Express: 393, Jang: 396).In terms of space or area Dawn has given more space to these photos; though in numbers these photos are less in English newspapers but they are generally appear in large sizes. There is not much difference in The News and Nawa-i-waqt. Though number of photos in Express (Urdu) are higher but space allocated to them is less as these photos generally appear in small sized. (See table 1)

Table 1. Space given to Photographs in each Newspaper

\begin{tabular}{ccccccc}
\hline & \multicolumn{3}{c}{ English Newspapers } & \multicolumn{3}{c}{ Urdu Newspapers } \\
\cline { 2 - 6 } & Dawn & The News & Express(eng) & Nawa-i- & Express & Jang \\
Total & $27827 \mathrm{~cm}^{2}$ & $24117 \mathrm{~cm}^{2}$ & $25216 \mathrm{~cm}$ & $24794 \mathrm{~cm}^{2}$ & $21228 \mathrm{~cm}^{2}$ & $23438 \mathrm{~cm}$ \\
\hline
\end{tabular}

\subsection{RQ1: How Flood 2010 is visually framed in National newspapers?}

To study visual framing of flood 2010 prominent themes/frames are observed. Moreover it was analyzed that how much misery and death is used as a subject in pictures to catch attention of reader.

\subsubsection{Prominent Frames/themes}

To study different prominent frames/themes there were divided in three categories of Human interest frames, economic and political frames.

Table 2. Difference in use of frames in national newspapers

\begin{tabular}{|c|c|c|c|c|c|c|c|}
\hline \multirow{2}{*}{ Prominent Frames } & \multicolumn{6}{|c|}{ Newspaper Names } & \multirow{2}{*}{ Total } \\
\hline & Dawn & Express(eng) & The News & Nawa-i-waqt & Express (urdu) & Jang & \\
\hline Human Interest & 165 & 153 & 139 & 175 & 143 & 156 & 931 \\
\hline Economic & 157 & 127 & 91 & 78 & 77 & 81 & 611 \\
\hline Political Frame & 61 & 63 & 59 & 99 & 173 & 159 & 614 \\
\hline Total & 383 & 343 & 289 & 352 & 393 & 396 & 2156 \\
\hline
\end{tabular}

It was observed that $43.1 \%$ (931 photos) were framed using human interest angle, $28.3 \%$ ( 611) photos were used using economic frames and $28.4 \%$ (614 photos) were framed using political theme.(see table 2) All newspapers were also somewhat different from each other in framing this issue. Political frame is more emphasized in Urdu newspapers. 
Political frame is more dominant in express (Urdu) and Jang. In both newspapers political leaders and parties are framed providing aid and sympathy to affectees. There is very little Coverage given to NGO sector work in visuals.

Human interest frame is more prominent in Dawn newspaper and Nawa-i-Waqt. Themes used in human interest framing are generally revolves around portraying grief of people on destruction of their homes, showing people in water to save themselves \& their families etc. Similarly dawn \& Express (eng) are dominant in using economic frame. . Downey, Johnson \& Brewer (2011) also argued in their study on Japanese Tsunami that "By approximately two-thirds to one-third, people were present in more photos than were not. In other words, approximately a third of the photos were of landscapes. An explanation for this could be as simple as news agencies wanting to show scope of the destruction."

Table 2.1. Comparison of English \& Urdu Newspapers in Visual Framing

\begin{tabular}{lll}
\hline Prominent Frames & English Newspapers & Urdu Newspapers \\
\hline Huma.n interest & $49.1 \%$ (457 photos) & $50.9 \%(474$ photos $)$ \\
Economic & $61.4 \%$ (375 photos) & $38.6 \%(236$ photos $)$ \\
Political & $29.8 \%(183$ photos $)$ & $70.2 \%(431$ photos $)$ \\
\hline
\end{tabular}

It was observed in table 2.1 that Human interest frame depicting grief, misery of people and destruction are dominant in Urdu news media but there is not much difference from English news media. On the other hand political frame is much dominant in Urdu news media and economic frame is much dominant in English news media. Overall emotional theme showing grief and destruction is much common in all photographs

\subsubsection{Depiction of Death/Misery}

To understand that how much dead bodied, mutilated bodies and misery of people over their dead ones is used as a theme in photographs of flood 2010 following results are found.

Table 2.2. Depiction of Death

\begin{tabular}{lccc}
\hline & $\begin{array}{c}\text { Dead Body } \\
\text { Depicted }\end{array}$ & $\begin{array}{c}\text { Mutilated } \\
\text { bodies }\end{array}$ & $\begin{array}{c}\text { People Grieving } \\
\text { Over Dead Body }\end{array}$ \\
\hline English Newspapers & 0 & 0 & 4 \\
Dawn & 1 & 0 & 7 \\
The News & 3 & 0 & 9 \\
Express (eng) & & & \\
Urdu Newspapers & 7 & 0 & 10 \\
Express(urdu) & 9 & 0 & 11 \\
Nawa-i-waqt & 11 & 0 & 17 \\
Jang & 31 & 0 & 58 \\
\hline Total & & &
\end{tabular}

While studying depiction of death it was found that there is no single photo framing mutilated bodies. There are only 4 photos depicting dead body in English Newspapers and 27 photos of dead body in Urdu Newspapers. There are only 58 photos showing people grieving over their dead ones; 20 in English news media and 39 in Urdu newspapers.

4.2 RQ2: In which role male \& female subjects are framed in visuals of all four newspapers while covering this disaster.

Only those photographs were observed in which male \& female subjects are present dominantly. Out of all the sample photos only 853 photos are those in which male \& female subject are present dominantly. Firstly to observe that which subject is dominant while framing visuals of flood 2010; presence of male \& female subjects is measured.

Table 3.1. Presence of Male \& Female subject

\begin{tabular}{lcc}
\hline & Frequency & Percentage \\
\hline Dominant Presence of female subject & 366 & $43 \%$ \\
Dominant Presence of male subject & 487 & $57 \%$ \\
\hline
\end{tabular}


It was observed that male subject is more dominant than female subject in photographs appeared in national newspapers of flood 2010.Only in $43 \%$ photographs female subject were present dominantly but male subjects were present dominantly in $57 \%$ photographs. (See table 3.1). The photographs are gender stereotyped in terms that male character is present in large number of photographs and female character is very less photographed.

Now 366 photographs in which female subjects are present, their role is observed; either they are framed active participant or passive participant.

Table 3.2. Role of male \& female Subject

\begin{tabular}{lcc}
\hline Role of Subject & Frequency & Percent \\
\hline Role of Female subject & & \\
Active Role & 117 & $32 \%$ \\
Passive Role & 249 & $68 \%$ \\
Total & 366 & $100 \%$ \\
Role of Male Subject & & \\
Active Role & 341 & $70 \%$ \\
Passive Role & 146 & $30 \%$ \\
Total & 487 & $100 \%$ \\
\hline
\end{tabular}

It was found that $68 \%$ (249 photos) females are framed in passive role as dependent on male member, sitting and only grieving and not actively doing anything but waiting for help. But on other hand 32\% women are framed in active role; rescuing their children, bringing food and helping their male counterpart. It was observed that male subject is mainly seen in active role. Out of 487 photos in which male subjects are present; in 70\% photographs male subjects are portrayed in active role and 30\% photographs male subjects are framed in passive role. (See table 3.2)

A Chi square test is conducted to observe difference in role of women and role of men. The results are very significant for role of women with $p=0.00$ and chi square value $(1)=27.25$. 143.21.

Similarly for role of men the results of Chi square test were also significant with $p=0.01$ and chi square value $=$

The photographs are gender stereotyped in terms that women are portrayed as dependent on men and shown as passive member of this disaster. Also those women who are involved in rescue activities are not highlighted much but on other hand men are shown in very active role and they look like they are not much in trouble and their passive role is not much highlighted.

\section{Discussion \& Conclusion}

Photograph is very critical when portraying disaster as it visually represents the text or news story and brings readers very close to actual event or disaster hit area and can touch their feeling by making them to experience that destruction through visuals. This study explored the framing of news on natural disaster through these visual representations that was not a neutral account of reality as Kruif (2009) argued.

The aim of the research was to determine the most prominent frames that were used by newspapers in reporting the Flood 2010 in Pakistan. Observing the media's behavior and keeping research on media construction of reality (framing) in mind, the researcher was interested in studying the portrayal of gender stereotype in the photographs. Depiction of death in newspaper images of disaster was another point of interest to the researcher.

Visual framing studied in present study is in line with the research by Borah \& Bulla (2006), who did comparative analysis on visual coverage of Tsunami and Hurricane Katrina. The prominent frames of human interest (sympathy gaining), economic (aid assisting \& economic destruction) and politics, found by the researcher were to an extent similar to the previously explored visual frames. The researcher found that human interest framed is commonly used by all newspapers in photographs of flood 2010. After that economic and then political frame is common. In Urdu newspaper political frame is more dominant than English media. The reason can be many.One of them may be the difference in language. A small literate fraction of Pakistani society can read and write English. This fraction is considered to be more objective and intellectual. Therefore, English newspapers tend to be more intent and precise while reporting and presenting news. They follow western style of press publications. On the contrary, Urdu journalism in Pakistan is more relevant to its society with greater circulation. Their style of presentation and interpretation of news is different often followed by prominent political slant. 
Another reason could be the editorial policy of the newspapers. It may include: to highlight or to exclude something from reality, size and placement of photograph in a newspaper, preference of one image over the other, editing practices of photojournalists in accordance with organization policies, or just the angle of shot selected out of many images taken at the same time. This is supported by the studies of Messaris \& Abraham (2001), Kruif (2009), and Fahmy (2004).

Frames of aid assistance and sympathy were most frequent in all newspapers. If these images were not shown, most of the nations would never have been moved to take action in giving millions of dollars of aid. Same is true in the case of nationwide and local aid provided by politicians, social activists, celebrities, community centers, educational institutions and general public. Government activity in relief projects was fueled up by the visual coverage.

Although it is beyond the scope of this study, it was interesting to note that captions written for the photographs also contribute towards the framing of reality. A few of the photographs were same in all four newspapers but had different captions. In addition to the difference of camera angle, size and placement, caption under these photographs were different too.

Bersak (2006), Borah \& Bulah (2006) and Dear (2006) found images of dead bodies and private grief over death bodies in the visual coverage of natural and man-made disasters carried in different countries. Unlike previous researches, very less depiction of death was found in English Pakistani newspapers( 4 photos) and only 27 photos of dead bodies were found in Urdu newspapers and only 58 photos out of 2156 were found framing relatives grieving over dead bodies. The difference in Urdu and English media can be because Urdu media is more towards sensationalism and English media is more inclined towards western journalism practices. But overall in all national newspapers depiction of death is very less as compared to previous studies. This shows that responsible and ethical journalism is being practiced in Pakistan. The reason may also be the code of conduct agreed upon by leading news channels and newspapers of Pakistan in year 2009. The purpose was to avoid broadcasting footages and publishing images of dead bodies and wounded people while covering the terror incidents.

The results of the present study regarding the portrayal of male \& female or gender stereotype in photos of flood are supported by Fahmy's (2004) study on portrayal of Afghan women. All four newspapers portrayed women as passive, dependent and weak victim of the disaster sitting around and waiting for others to help. While, active role of men was shown by strong and independent male sufferers of the flood working for rehabilitation. Feature photos enclosed women and children more frequently whereas, business and economic news stories were published with masculine images. Moreover there were very less photos in which women are depicted. The reason can be that Pakistan is male dominant society and here women and men in rural areas are strictly separated; so to photograph women is also much difficult as compared to male subjects. Overall these photos are gender stereotyped in all national newspapers.

Overall this study cannot be generalized as it is at exploratory level so for future it was recommended that a study using longer time frame could give a better view of the coverage. The themes of framing could be studied with more detailed categories. A study on the audience's interpretation of visual coverage and media effects will be beneficial in learning about visual framing i.e. linking content analysis and survey data. Moreover the study has used census sampling method; so for future a detailed study can be done by using systematic way of sampling.

\section{References}

Borah, P., \& Bullah, D. (2006).Visual framing of the Indian Ocean Tsunami and Hurricane Katrina: A comparison of coverage in newspapers in three countries'. Retrieved on $6^{\text {th }}$ dec 2011 from all academics .com.

Bryant, J. \& Oliver, M. B. (2009) Media effect: Advances in Theory and Research. 3rd Edition. New York: Routledge/Taylor \& Francis

Kahle, S. , Yu, N. \& Whiteside, E. (2007). Another Disaster: portrayals of race in Hurricane Katrina coverage. Visual Communication Quarterly, volume: 14, issue: 2, pages 75-89.

Dear, M. (2006).Remember Katrina: But Please, No Photos of Dead People', Space and Culture, volume: 9, issue: 1, pages 89-91

Downey R, Johnson E \& Brewer B(2011). Through the Lens: Visual framing of Japan Tsunami in US, British \& Chinese Online media.Paper presented at the internation Symposium on online journalism , Austin, TX. Retrieved December 2011

Entman, R. M. (2010). Media framing biases: slant in the news of campaign of 2008, Journal of Journalism, volume: 11 , issue: 4, pages 389-408.

Fahmy, S. (2004).Picturing Afghan Women: Content Analysis of Wire Photographs during the Taliban Regime and after the Fall of the Taliban Regime. Gazette, volume: 66, issue: 2, pages 91-112.

Fahmy S ; J. D Kelly, Young Soo (2007) . What Katrina revealed. A visual coverage of Hurricane Katrina by US newspapers and wire services. Journal of Journalism \& Mass communication, 84 , pages 546-561.

Fujioka, Y. (1999). Television Portrayal and African-American Stereotypes: Examination of television effects when direct contact is lacking. Journalism and Mass Communication Quarterly, 76, pages 52-75.

Hafez, K. (2002). Journalism Ethics: Comparison of Ethics Codes in North Africa, Middle East Europe, and Muslim Asia. Political Communication, volume: 19 , pages $225-250$. 
Jackson, J. H. (2011). Envisioning disaster in the 1910 Paris flood. Journal of Urban History, 37, 176-207.

Kruif, J. De (2009). Death Shall Have No Dominion:Disasters by Dutch Flood in the Press. Edizioni Plus - Pisa University Press, Lungarno Pacinotti, 43, pages 91-121

Lester, P. M. \& Ross S. D. (2003).Images that Injure: Pictorial Stereotypes in the Media. 2nd Edition. Greenwood Publishing Group.

Littlefield \& Quentte (2007) Potrayal of authority by media in natural disasters: crisis leadership \& Hurricane Katrina. Journal of communication research.35, page no 26-47.

Matthes J(2009) Whats a frame ? A content analysis of media framing studies in leading communication journals, 1990-2005. Journal of Journalism \& Mass Communication. 86 page no 349-367.

Peng Z (2004). Picturing china: content analysis of photo coverage in the New York Times

and Los Angeles Times. International Communication Association. Issue 1

Teawkesbury and Schefuelle (2009). News framing theory \& Research in J. Bryant and M. B Olivers (Ed) of Advances in theory \& research. New York : Routledge. Page no 17-33

National Disaster Management Authority, Pakistan, (2010). Available at: http://www.ndma.gov.pk (Accessed: Dec. 06, 2011).

Pakistan Floods Relief, Recovery and Rehabilitation, (2010), Damages and Losses.

Available at: http://pakistanfloods.pk (Accessed: Jan, 03, 2011).

Wojdynski (2009) Interactive Newspaper: Online multimedia \& Framing of Iraq war. Retrieved from 6 $6^{\text {th }}$ dec 2011 from all academics.com. Conference paper.

Eckler \& Yusuf(2010). International Journalists expectation from the Us media coverage of Hurricane Katrina. Journal of Journalism ; 11 page no 277-292.

Rodgers S.,Kenix.J.L.,Thorson E. (2006),Manuscript submitted for peer review to Mass Communication \& for a third peer review March,2006. Retrieved from http://ir.canterbury.ac.nz/on Dec, 2011 